\title{
The Effect of Chinese Cultural Values in Counterfeit Luxury Goods Purchase
}

\author{
Sheng FANG \& Xiaojing LU \\ Wuhan University, China
}

\begin{abstract}
Though there have been a few studies on counterfeit luxury purchase, the effect of cultural values, especially Chinese cultural values, in counterfeit luxury purchase remained unclear. This study selected five Chinese cultures values, found out five most discussed psychological determinants in luxury counterfeits purchase, and then created a Chinese cultural values - psychological determinants of counterfeit luxury brands purchase model, to analyze the relations between the two.

KEYWORD: Counterfeit luxury purchase, Chinese cultural values, face consciousness, other orientation, long-term orientation, sense of righteousness, pragmatism
\end{abstract}

\section{INTRODUCTION}

Counterfeit goods have become one serious problem in world economy today, especially in China. The nation is blamed to be the number one counterfeiter nation in the World - both for exports and for consumption within their own domestic market (PR Newswire US, 2015). International Anti Counterfeiting Coalition (IACC) estimated some $80 \%$ of all counterfeit branded products are thought to originate in China.

Luxury and counterfeit luxury consumption, including factors influencing counterfeit luxury purchase, have been studied by western and eastern scholars for long. Though some scholars have pointed out cultural factors were important in understanding custom purchase behavior towards counterfeit luxury brands (e.g. Eisend \& SchuchertGüler, 2006) and some more did empirical studies on cultural values such as face consciousness (e.g. Chen, Zhu, Le \& Wu, 2014), we would say our knowledge about the role of Chinese cultural values in counterfeit luxury purchase was still very limited. This paper tries to fill up this research gap by providing a model of the functioning mechanism of culture values in counterfeit luxury goods purchase.

\section{LITERATURE REVIEW}

One important direction of existing studies was about the factors influencing counterfeit luxury purchase. However, cultural factors were missing in most of these studies.

Eisend and Schuchert-Güler (2006) reviewed a number of existing studies on the determinants of consumers' intention to purchase counterfeit products and developed a model aiming to provide a framework for future research endeavors. In this model, they summarized the main antecedents of purchase of counterfeit products into four categories, namely person, product, purchase situation as well as social and cultural context. However, they failed to explain cultural factors' functions in details because the existing literatures they reviewed failed to do so, too. Thus, they asserted "Investigating cultural differences seems a promising further approach when researching determinants of counterfeiting." (Eisend \& Schuchert-Güler, 2006)

Chen et al. (2014) conducted three laboratory experiments to determine how the face consciousness would influence consumption of counterfeit luxury goods. The results showed that participants' face consciousness had a significant positive influence on intention to purchase counterfeit luxury goods. But in their study, only one Chinese cultural value was studied though it's widely considered one of the most significant one in purchase decision.

Wan et al. (2009) proposed a model that takes specific consumer values as the mediators between key traditional Chinese cultural values and the intention to buy pirated CDs. Besides face consciousness, another cultural value otherorientation was also included. Their conclusion was 
pirated CDs were more acceptable to those with face consciousness and the cultural value of otherorientation might impede the purchase of pirated CDs by means of its negative effect on materialism.

Though they argued the two cultural values studied were more relevant to Chinese consumer behaviors, citing $\mathrm{Li}$ and $\mathrm{Su}$ (2007), it couldn't disguise the fact that a lot Chinese cultural values were missing than knowing. Also, CDs, a knowledge product, were different from luxury products essentially.

But the model Wan et al. (2009) proposed would be meaningful for further research including this study (See Figure 1).

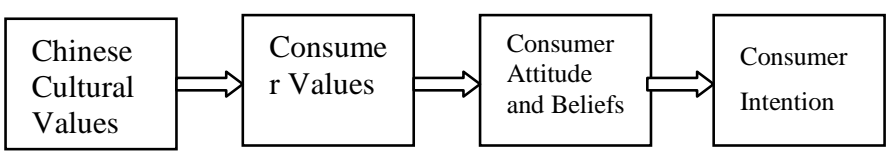

Figure 1: Cultural Values-Consumer Intention Model

The paper would borrow this framework to form our own model about the relations of Chinese cultural values and psychological determinants.

\section{CHINESE CULTURE VALUES}

Culture is a very complex construct. Cultural values establish the norms or standards by which everything in a society is judged and are important in explaining consumption (Fan, 2000). But in counterfeit luxury research, cultural factors were far from fully discussed. These missing cultural value researches might help us to understand the role of other determinants in luxury consumption better (Eisend \& Schuchert-Güler, 2006; Trinh \& Phau 2012). For example, previous studies on materialism's role in counterfeit consumption found inconclusive results (Wilcox, Kim \& Sen, 2009; Wan et al., 2009; Lu \& Lu, 2010). Reasons such as cultural background may explain this occurrence (Trinh, \& Phau, 2012).

Chinese cultural values have been found very different from the western cultural values in many aspects by pervious researches. Yau (1988), adopting Kluckhohn and Strodbeck's (1961) pattern, classified Chinese cultural values into five categories.

(1) man-nature orientation (harmony with the nature, yuarn); (2) man-himself orientation (abasement, situation-orientation); (3)relational orientation (respect for authority, interdependence, group-orientation, face); (4) time orientation (continuity, past-time orientation); and (5) personal activity orientation (the doctrine of the mean, harmony with others).

After consulting a number of Chinese social scientists, the survey of the Chinese Culture Collection (1987) developed a list of 40 key Chinese cultural values. Fan (2000) added 31 values more and produced a new list of Chinese culture values grouped under eight categories of: national traits, interpersonal relations, family (social) orientation, work attitude, business philosophy, personal traits, time orientation and relationship with nature.

No matter using the 71 values by Fan (2000), the 40 values by the Chinese Culture Collection (1987) or the 11 values by Yau (1988), it is necessary that we find out the values mostly influence the Chinese consumption behavior, especially the ones dominating in their consumption decision making process like purchasing the counterfeit luxury goods, before our study in finding the relations between cultural values and psychological determinants.

With thorough readings on Chinese traditional cultures and consulting the suggestions of five professors on Chinese cultures and marketing, the author selected the following five Chinese cultural values as the major ones which may influence counterfeit luxury brand purchases:

Face consciousness, other orientation, long-term orientation, sense of righteousness and pragmatism Explanations and discussions on their roles will be given later.

\section{PSYCHOLOGICAL DETERMINANTS}

There have been a few studies on luxury counterfeits consumption. The author read through the major studies in recent five years on psychological determinants of luxury counterfeits purchase, and found the most discussed personal traits influencing luxury counterfeit purchase are:

Materialism: Richins and Dawson (1992) defined materialism as "the importance ascribed to the ownership and acquisition of material goods in achieving major life goals or desired states."

Integrity: Integrity is determined by personal ethical standards and obedience to the law. (Ang et al., 2001; Wang et al., 2005)

Value consciousness: Lichtenstein, et al. (1990) defines value consciousness as a concern to pay in a low price, while expecting to a certain quality constraint. Consumers that are value conscious will consider the quality of the product and the money they spend to buy it (Hidayat \& Diwasasri, 2013).

Social influence: Social influence reflects on what others judgment of an individual consumer's behavior (Ang et al., 2001). Depending on their social group norm, the pressure from referent groups can induce the consumer's decision to use original or counterfeits of luxury brands (Bearden et al., 1989). A similar concept is social factors.

Self-image consciousness: Self-image concerns itself with issues like "how I am seen by others" (Sirgy and Danes 1982). Fengstein, Scheir and Buss (as cited by Burnkrant and Page, 1985) define public 
self-consciousness as the "individual's awareness of self as a social object". A relative concept is status consumption.

\section{CULTURAL VALUE-PSYCHOLOGICAL DETERMINANTS RELATION}

After finding out the most common psychological determinants in counterfeit luxury purchase and the Chinese cultural values may influence in this process, we are now able to illustrate why and how these cultural values matter.

Face consciousness: Face is a concept of central importance in Chinese cultural values because of its pervasive influence in interpersonal relations among Chinese (Yau, 1988). Actually in previous studies, face consciousness has been identified as one of the most robust cultural values that affect Chinese consumer behaviors (Bao et al., 2003; Li and Su, 2007, Chen et al., 2014). Face may be obtained either through personal qualities, or derived from non-personal characteristics, such as wealth, social connections and authority through personal efforts. Consumers with face consciousness like to use luxury products and named brands to gain "face." Therefore, material products serve as instruments for them to achieve this goal (Wan et al., 2009). Also, face consciousness leads to emphasis on self-image to bring more "face", either through personal or nonpersonal qualities.

Other Orientation: Hofstede (1980) indicated that the Chinese, as well as Asians, are very collectivistic. Chinese are also believed to be conformity-oriented, meaning customers are susceptible to social influences and group pressure. They are considerate and accommodating and being able to see something from the perspective of another person.

Long-term orientation: Long-term orientation is a concept about the degree the society embraces or does not embrace long-term devotion to traditional, forward thinking values (Hofstede, 1980). In Hofstede's (1980) research, the Chinese are highly long-term orientated. This could explain why the Chinese prefer to buy property and have high saving rate. Long-term orientation makes Chinese tend to save for tomorrow and might affect materialism.

Sense of righteousness: Sense of righteousness or integrity is one of the merits traditional Chinese culture promotes. This sense directly leads the development of customer ethics or integrity. Previous studies have shown that customers with high customer ethics tend to refuse counterfeits.

Pragmatism: Being pragmatic means of or relating to a practical point of view or practical considerations. This value may induce customers with value consciousness to think luxury brands don't deserve the money. It also might become barriers for materialism and social influence. So it may become an antecedent of counterfeit purchase. On the basis of the above discussions on Chinese cultural values and psychological determinants of counterfeit luxury purchase, we adopted Wan et al's (2009) model and developed the following Chinese cultural values--psychological determinants of counterfeit luxury brands purchase model (Figure 2).

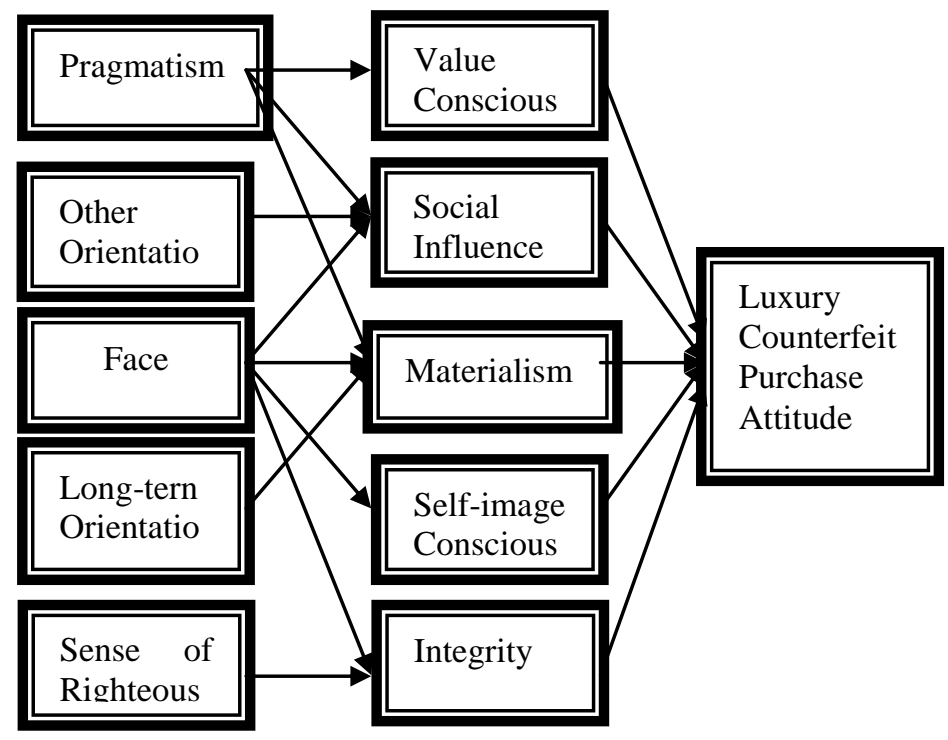

Figure 2: Chinese cultural values - psychological determinants of counterfeit luxury brands purchase model

\section{CONCLUSION}

This study selected five Chinese cultures values and found out five most discussed psychological determinants as well as the relations between the cultural values and the determinants. It created a Chinese cultural values - psychological determinants of counterfeit luxury brands purchase model and filled in the gap of previous studies.

For further research, empirical studies could be conducted to find out the exact roles (positive or negative) of these cultural values in forming the psychological values and subsequently in counterfeit luxury consumption.

Also, though this paper linked up the cultural values with psychological traits of consumers, there're some more relations demanding elaborate researches. For example, in the paper by Chen et al (2014), the products' usage occasion and brand prominence were studied as moderators of the influence of face consciousness. By the four categories from Eisend and Schuchert-Güler (2006), they belong to situational and product-related factors respectively. This indicated more factors, like consumer mood or luxury advertisement, could be studied as moderators of cultural values toward purchase attitude and intention of luxury counterfeits, which will enhance our understanding of the luxury counterfeit consumption overall. 


\section{REFERENCES}

[1] Ang, S. H., Cheng, P. S., Lim, E., \& Tambyah, S. K. (2001). Spot the Difference: Consumer Responses towards Counterfeits. Journal of Consumer Marketing, 18(3), pp219-235.

[2] Bao, Y., Zhou, K. Z. \& Su, C. (2003). Face Consciousness and Risk Aversion: Do They Affect Consumer Decision-Making? Psychology \& Marketing, 20(8), pp733-755.

[3] Bearden, W. O., Netemeyer, R. G. \& Teel, J. E. (1989). Measurement of Consumer Susceptibility to Interpersonal Influence. Journal of Consumer Research, 15 (4): pp473 481.

[4] Burnkrant, R.E., \& Page, T.J. 1985. A modification of Fenigstei, Scheler and Bass Selfconsciousness Scale. Journal of Personality Assessment, 48(6): pp629 - 637.

[5] Chen, Y., Zhu, H., Le, M., \& Wu, Y. (2014). The Effect of Face Consciousness on Consumption of Counterfeit Luxury Goods. Social Behavior \& Personality: an International Journal. Vol. 42 Issue 6, pp1007-1014.

[6] Eisend, M., \& Schuchert-Güler, P. (2006). Explaining Counterfeit Purchases: A Review and Preview. Academy of Marketing Science Review, No. 12, pp1-25.

[7] Fan, Ying. (2000). A Classification of Chinese Culture. Cross Cultural Management: An International Journal, Vol. 7 Iss 2 pp.3-10.

[8] Hidayat, A. \& Diwasasri, A. H. A., (2013). Factors Influencing Attitudes and Intention to Purchase Counterfeit Luxury Brands among Indonesian Consumers. International Journal of Marketing Studies; Vol. 5, No. 4, pp761-768.

[9] Hofstede, G. (1980). Cultures' consequences. Sage Publications, London.

[10] Kluckhohn, F.R. \& Strodbeck, F.L. (1961). Variations in Value Orientation, Row, Paterson and Co, Illinois.

[11] Lichtenstein, D. R., Netemeyer, R. G., \& Burton, S. (1990). Distinguishing Coupon Proneness from Value Consciousness: An Acquisition-Transaction Utility Theory Perspective. Journal of Marketing, 54, pp54-67.

[12] Li, J. J. \& C. Su. (2007). How Face Influences
Consumption: A Comparative Study of American and Chinese Consumers. International Journal of Market Research 49(2), pp237-256.

[13] Lu, L. C. \& Lu, C. J (2010). Moral Philosophy, Materialism and Consumer Ethics: An Exploratory Study in Indonesia. Journal of Business Ethics, 94(2), pp193210.

[14] PR Newswire US.(2015) Anti-counterfeit and Brand Protection - Luxury Products, Beauty Products and Apparel: Potential synergies in shared marketing and distribution. 01/27/2015

[15] Richins, M. L. \& Dawson, S. (1992). A Consumer Values Orientation for Materialism and its Measurement: Scale Development and Validation. Journal of Consumer Research, 19(Dec), pp303-316.

[16] Sirgy, M. J., \& Jeffrey E. D. (1982). Self-Image/ProductImage Congruence Models: Testing Selected Models. Advances in Consumer Research, 9, pp556-561.

[17] The Chinese Culture Connection (1987). "Chinese values and the search for culture-free dimensions of culture." Journal of Cross-Cultural Psychology, 18:2, pp.143-164.

[18] Trinh, V., \& Phau, I. (2012). The Overlooked Component in the Consumption of Counterfeit Luxury Brands Studies: Materialism: A Literature Review. Contemporary Management Research. Sep, Vol. 8 Issue 3, pp251-263.

[19] Wang, F., Zhang, H., Zang, H., \& Ouyang, M. (2005). Purchasing pirated software: an initial examination of Chinese consumers. Journal of Consumer Marketing, 22(6), pp340-51.

[20] Wan, W. W. N., Luk, C. L., Yau, O. H. M., Tse, A. C. B., Sin, L. Y. M., Kwong, K. K., \& Chow, R. P. M. (2009). Do traditional Chinese Cultural Values Nourish a Market for Pirated CDs? Journal of Business Ethics, 88(1), pp185-196.

[21] Wilcox, K., Kim, H. M., \& Sen, S. (2009). Why do Consumers Buy Counterfeit Luxury Brands. Journal of Market Research, 46(2), pp247-259.

[22] Yau, Oliver H. M. (1988). Chinese Cultural Values: Their Dimensions and Marketing Implications. European Journal of Marketing, Vol. 22 Iss 5 pp. $44-57$ 